\title{
Relationship Between ABO and Rhesus Blood Groups and Susceptibility to Asthma Within Sokoto Metropolis, Nigeria
}

\author{
Moses Nnaemeka Alo", Ukpai Agwu Eze ${ }^{2}$, *, Saidu Abdulhi Yaro ${ }^{3}$, Bello Jubril ${ }^{3}$, \\ Nelson Nnanna Nwanoke ${ }^{4}$ \\ ${ }^{1}$ Department of Biological Sciences/Microbiology/Biotechnology, Faculty of Science and Technology, Federal University Ndufu-Alike, Ikwo, \\ Ebonyi State, Nigeria \\ ${ }^{2}$ Department of Medical Laboratory Sciences, Faculty of Health Sciences, Ebonyi State University, Abakaliki, Nigeria \\ ${ }^{3}$ Department of Immunology, Faculty of Medical Laboratory Sciences, Usmanu Danfodio University, Sokoto, Nigeria \\ ${ }^{4}$ Department of Chemical Pathology, Federal Teaching Hospital, Abakaliki, Ebonyi State, Nigeria
}

\section{Email address:}

ukpai.eze@ebsu-edu.net (U. A. Eze)

\section{To cite this article:}

Moses Nnaemeka Alo, Ukpai Agwu Eze, Saidu Abdulhi Yaro, Bello Jubril, Nelson Nnanna Nwanoke. Relationship Between ABO and Rhesus Blood Groups and Susceptibility to Asthma Within Sokoto Metropolis, Nigeria. International Journal of Immunology.

Vol. 3, No. 3, 2015, pp. 37-41. doi: 10.11648/j.iji.20150303.12

\begin{abstract}
Asthma is the result of chronic inflammation of the airways which subsequently results in increased contractability of the surrounding smooth muscles. This among other factors leads to bouts of narrowing of the airway and the classic symptoms of wheezing. As at 2011, World Health Organisation (WHO) reported that approximately 235 million people worldwide were affected by asthma. This study aims to evaluate and determine the susceptibility of ABO and Rh blood groups to asthma. A total of 200 clinically confirmed asthmatic patients and 100 apparently healthy individuals within Sokoto metropolis were prospectively enrolled and their blood group status were determined using red blood cell agglutination method. In this research work, the result obtained shows that 74 asthmatic patients constituting $37.0 \%$ out of the total 200 patients who participated in the study are blood group A, $56(28.0 \%)$ are blood group B, $26(13.0 \%)$ are blood group AB and $44(22.0 \%)$ are blood group O. For Rh blood group, out of the 200 study subjects, $181(90.5 \%)$ are Rh positive and $19(9.5 \%)$ are Rh negative. Among 100 control participants 26 (26.0\%) have A blood group, 24 (24.0\%) have B blood group, 2 (2.0\%) have AB blood group, and $48(48.0 \%)$ have O blood group. No statistical difference was observed between Rh system in study subjects and controls, but blood group A was significantly higher in asthma patients compared to controls $(\mathrm{P}<0.05)$.
\end{abstract}

Keywords: Asthma, ABO Blood Group, Rhesus Blood Group, Nigeria

\section{Introduction}

Asthma is known to be a common chronic inflammatory disease of the airways and the cause is incompletely understood [3]. This continuous inflammatory response may result to a permanent airway obstruction. Several hypothesis have been put forward on the cause of asthma and many point to the interaction between many genetic and environmental factors which influence the tone or reactivity of the airways $[14,15]$. The condition is characterised by recurring wheeze, shortness of breath, chest tightness and cough which varies with time and intensity, and often severe at night $[3,4,23]$

The ABO histo-blood group system is one of the genetic risk factors linked to the susceptibility to asthma in some populations. Independent studies have analysed the importance of this system in both children and adults in respect to asthma. One such study found statistically significant differences in the frequencies of the $\mathrm{ABO}$ and related secretor phenotypes in Australian adults [16] and another reported a greater incidence of A and B red blood cell phenotypes in patients with different atopical conditions compared to controls [8]. Associations between the ABO and Secretor systems and asthma have also been observed in Italian [17] and Taiwanese children [7] but not in Indian adults [9]. In a study in Georgians, markers for bronchial asthma and pollinosis showed that the risk for the development of severe bronchial asthma was higher in 
patients with blood type $\mathrm{B}$ whereas in blood type $\mathrm{O}$, a mild to moderate degree of severity of was more characteristic [13].

The composition of the glycoconjugate profile of the respiratory epithelium and of the exocrine secretions is controlled, at least in part, by epistatic interactions between the ABO (ABO; 9q34.1) and Secretor (FUT2; 19q13.3) genes and influenced by their polymorphisms [18]. As these profiles represent important risk factors for the adherence of microorganisms and allergens, it is possible that the action of the set of ABO and FUT2 genes influence the susceptibility to other respiratory diseases apart from asthma [19].

Studies evaluating the relationship between ABO blood group status and atopic diseases have appeared in the literature since the late sixties. Apparent discordant results have been reported. In 1964, the observation that ABO agglutinins are present in a wide variety of pollens from grasses, flowers and trees, raised the possibility that these agglutinins might interact with cells containing blood group antigens in the respiratory epithelium, an effect that would be neutralized in secretor patients [5].

According to World Health Organisation (WHO), approximately 235 million people worldwide were affected by asthma in 2011 [20] and approximately 250,000 people die per year from the disease. Low and middle income countries make up more than $80 \%$ of the mortality [20]; rates vary between countries with prevalence between 1 and $18 \%$. It is more common in developed than developing countries. One thus sees lower rates in Asia, Eastern Europe and Africa. Within developed countries, it is more common among those who are economically disadvantaged while in developing countries, it is more common amongst the affluent. The reason for these differences is not well known [20].

The prevalence of childhood asthma in the United States has increased since 1980, especially in younger children. Rates of asthma have increased significantly between the 1960s and 2008 [21] and have been recognised as a major public health problem since the 1970s. In 2005, asthma affected more than 22 million people, including 6 million children, and accounted for nearly 500,000 hospitalizations that same year [22].

The studies assessing the relationship between $\mathrm{ABO}$ and Rhesus blood groups and asthma is very scarce in Nigeria. Therefore, this research was designed to explore the relationship of blood group type and susceptibility to asthma in Sokoto Metropolis, Nigeria.

\section{Materials and Methods}

\subsection{Study Design}

This study involves 200 asthmatic patients and 100 adults (control group) who attend the Pulmonary Unit of Usmanu Danfodiyo University Teaching Hospital, Specialist Hospital and Maryam Abacha Women and Children Hospital, all in Sokoto metropolis, Nigeria. Patients with renal or liver diseases, patients with diabetes mellitus or pregnant females, and asthmatic individuals living outside Sokoto Metropolis were excluded from this study.

\subsection{Ethical Consideration}

This research was approved by the Research Ethics Committee of the Faculty of Medical Laboratory Science of Usmanu Danfodiyo University, Sokoto, Nigeria. In addition, ethical clearance for the study was sought and obtained from the Research Ethics Committee of Specialist Hospital Sokoto, Maryam Abacha Women and Children Hospital and Usmanu Danfodiyo University Teaching Hospital (UDUTH), Sokoto. Patients' and controls' informed consents were also obtained before the commencement of the study. All information generated in this study were kept confidential except only for the purpose of this publication.

\subsection{Sampling and Laboratory Analysis}

The blood samples $(3 \mathrm{~mL})$ were taken directly from the vein (ante-cubital vein) with the help of a medical supervisor. The samples were collected in $\mathrm{K}_{2}$ EDTA vials and brought to the Haematology and Blood Transfusion Laboratory of the Faculty of Medical Laboratory Science of Usmanu Danfodiyo University, for analysis. $\mathrm{ABO}$ and $\mathrm{Rh}$ blood grouping were performed simultaneously. Red blood cell agglutination method was used for analysis of blood group. A drop of each antisera-A, antisera-B and antisera-D were placed on to clean, labeled glass slides and a drop of blood was added to each and mixed immediately. Agglutination with antisera-A showed A blood group, with antisera-B showed $\mathrm{B}$ blood group and with both $\mathrm{A}$ and $\mathrm{B}$ showed $\mathrm{AB}$ and with neither of these showed $\mathrm{O}$ blood group. Agglutination of blood with D showed positive test for D antigen.

\subsection{Statistical Analysis}

The data derived from this study was analysed using SPSS software version 18.0. The ABO and Rh phenotype of the asthmatic patients and controls were compared using Chi Square test of independence. $\mathrm{P} \leq 0.05$ was accepted as statistically significant.

\section{Results}

This study recruited two hundred patients with asthma and one hundred apparently healthy individuals attending the participating hospitals to ascertain the association between ABO Rh Blood groups and susceptibility to asthma.

Of the 200 asthmatic patients recruited, 74 (37.0\%) are blood group A, 56 (28.0\%) are blood group B, 26 (13.0\%) are blood group $\mathrm{AB}$ and $44(22.0 \%)$ are blood group $\mathrm{O}$. In the controls, 26 (26.0\%) have A blood group, 24 (24.0\%) have B blood group, 2 (2.0\%) have AB blood group, and 48 (48.0\%) have $\mathrm{O}$ blood group (Table 1).

Out of the 200 asthma patients, 181 (90.5\%) are Rh positive and $19(9.5 \%)$ are $\mathrm{Rh}$ negative. Among the 100 controls, $94(94.0 \%)$ are $\mathrm{Rh}$ positive and $6(6.0 \%)$ are $\mathrm{Rh}$ negative (Table 2). 
In comparing the number of subjects having $\mathrm{ABO}$ and $\mathrm{Rh}$ blood groups, the 74 patients with A blood group, 72 were Rh positive and 2 were $\mathrm{Rh}$ negative, for the 56 that had blood group B, 47 were $\mathrm{Rh}$ positive and 9 were $\mathrm{Rh}$ negative, for the 26 with $\mathrm{AB}$ blood group, 23 were Rh positive and 3 were $\mathrm{Rh}$ negative, and for the 44 patients that have O blood group, 39 were Rh positive and 5 were Rh negative (Table 3 ).

Table 1. The frequency distribution of $A B O$ blood group among the asthmatic patients and controls.

\begin{tabular}{lll}
\hline \multirow{2}{*}{ ABO Blood group } & Asthma patients & Controls \\
\cline { 2 - 3 } & Frequency (\%) & Frequency (\%) \\
\hline A & $74(37)^{*}$ & $26(26)$ \\
B & $56(28)$ & $24(24)$ \\
AB & $26(13)$ & $2(2)$ \\
O & $44(22)$ & $48(48)$ \\
Total & $200(100)$ & $100(100)$ \\
\hline
\end{tabular}

$* \mathrm{P}<0.05$

Table 2. The frequency distribution of Rh blood group among the asthmatic patients and controls.

\begin{tabular}{lll}
\hline \multirow{2}{*}{ Rh Blood group } & Asthma patients & Controls \\
\cline { 2 - 3 } & Frequency (\%) & Frequency (\%) \\
\hline Positive & $181(90.5)$ & $94(94)$ \\
Negative & $19(9.5)$ & $6(6)$ \\
Total & $200(100)$ & $100(100)$ \\
\hline
\end{tabular}

Table 3. The comparison of frequencies between ABO blood group and Rh blood group.

\begin{tabular}{llll}
\hline \multirow{2}{*}{ ABO Blood group } & \multicolumn{2}{l}{ Rh Blood group } & \multirow{2}{*}{ Total } \\
\cline { 2 - 3 } & Positive & Negative & \\
\hline A & 72 & 2 & 74 \\
$\mathrm{~B}$ & 47 & 9 & 56 \\
$\mathrm{AB}$ & 23 & 3 & 26 \\
$\mathrm{O}$ & 39 & 5 & 44 \\
Total & 181 & 19 & 200 \\
\hline
\end{tabular}

\section{Discussion}

Asthma is a chronic disease characterised by recurrent attacks of breathlessness and wheezing. As of 2011, approximately 235 million people worldwide were affected [20] and 250, 000 people die per year from the disease. Some of the studies conducted in Europe, Asia and United States shows that there is the relationship between $\mathrm{ABO}$ and rhesus blood group and susceptibility to asthma with varying rates of relationship, but limited or no publication is available in Nigeria.

In this research work, the result obtained shows that 74 asthmatic patients constituting $37.0 \%$ out of the total 200 patients who participated in the study are blood group A, 56 $(28.0 \%)$ are blood group B, $26(13.0 \%)$ are blood group AB and $44(22.0 \%)$ are blood group O. For Rh blood group, out of the 200 study subjects, $181(90.5 \%)$ are Rh positive and 19 $(9.5 \%)$ are Rh negative.

This result demonstrates that blood group A is more common and shows statistical significance among asthmatic patients $(\mathrm{P}<0.05)$. This is in agreement with the work by De la Vega and colleagues [6], who reported a high presence of blood group A among asthmatic patients but no difference was noted between $\mathrm{Rh}$ systems in both groups (study subjects and controls). Also the difference in the distribution of blood group $\mathrm{A}$ and $\mathrm{O}$ between control and asthmatic group in that study was found to be highly significant. The report of this study is also similar to the work of Brachtel et al [8], who studied 239 German patients with atopic conditions (atopic dermatitis, hay fever, allergic rhinitis, bronchial asthma, and acute urticaria) and reported that the incidence of blood group antigens A and B was potentially higher in patients than in controls. Similarly, Kauffmann and colleagues studied 228 coal miners with asthma and observed that lower lung function in blood group A, and in a lesser extent in blood group B [5]. However, Mozalevskii et al. [12], Nikitin et al. [11] and Khetsuriani et al. [13] reported that asthma from chronic lung inflammation is also more common in type B. In the same vein, the result of the current study differs from the findings by Bijanzaadeh et al [9] who observe that $\mathrm{O}$ blood group is more common among asthmatic patients followed by $\mathrm{B}, \mathrm{A}$, and $\mathrm{AB}$ blood groups. Perhaps in their study, non-significant difference between patients and controls was observed. According to Koers et al [10], blood type B tends to get pollen allergies more often than the other blood types. However, in their study no statistically significant difference between patients and controls was observed. In another study, blood group O/secretors ( $\mathrm{Se} / \mathrm{Se})$ and $\mathrm{O} / \mathrm{Le}(\mathrm{a}-\mathrm{b}-)$ were associated with childhood asthma, and may act as one of the predominant factors for environmental triggers of allergy for asthmatic children in Taiwan [7]. These differences may be as a result of different geographic location and the number of subjects studied.

Similarly, Manisha and Yadav in their study of the distribution of $\mathrm{ABO}$ and $\mathrm{Rh}$ (D) allele frequency among asthmatic patients, found that blood group $\mathrm{O}$ is more frequent in asthmatic patients compared to controls [2]. The O blood group was highest in asthmatic patients followed B and A. In both asthmatic patients as well as healthy subjects, they found that $\mathrm{Rh} \mathrm{D}^{+}$was more abundant than $\mathrm{Rh} \mathrm{D}^{-}$. In the same vein, Yesar et al. [1] reported a significant increase in the percentage of blood group $\mathrm{O}$ in comparison with other blood groups with no significant differences among the other groups (i.e. A, B and AB). In a related study by El-sobky et al. [24], blood group $O$ was also found to be more prevalent while group $\mathrm{AB}$ was the least prevalent among examined individuals.

Among the controls used in this study, 26 (26.0\%) have 'A' blood group, 24 (24.0\%) have 'B' blood group, 2 (2.0\%) have 'AB' blood group, and 48 (48.0\%) have 'O' blood group. The high frequency of blood group ' $\mathrm{O}$ ' among the controls is similar to other reports from Nigeria and therefore, the controls represent the correct $\mathrm{ABO}$ distribution. For instance, Egesie et 
al. [25] reported $\mathrm{ABO}$ percentage as $\mathrm{O}(49 \%)$, A (22\%), B $(22 \%)$ and B $(7 \%)$ in a study done in the Niger Delta. In Oyo State, $50 \%$ of the population surveyed were blood group 'O', $22.9 \%$ blood group 'A', $21.3 \%$ group 'B' and $5.9 \%$ were of the 'AB' blood group [26]. In Lagos, Adeyemo et al. [27] reported that 'O' blood groups had the highest percentage frequency (55.35), followed by blood group 'A' $(25.3 \%)$, group 'B' (16.7\%) and group 'AB' (2.7\%). Similarly, Omotade et al. [28] observed a percentage occurrence of $54.2 \%$ in blood group ' $\mathrm{O}$ ', $21.6 \%$ in blood group 'A', $21.4 \%$ in blood group 'B' and $2.8 \%$ in blood group 'AB'. They also observed that $\mathrm{Rh}$ (D) gene occurred in $95.2 \%$ while $4.8 \%$ were $\mathrm{Rh}$-negative in the individuals surveyed. Furthermore, Kulkarni et al. [29] analysed data $\mathrm{ABO}$ and Rhesus blood group from 43187 blood donors belonging to 34 ethnic groups, predominantly from northern Nigeria. Group ' $\mathrm{O}$ ' was found in $46.6 \%$ of all those examined. Group 'A' was found in $23.05 \%$ and Group 'B' in 25.95. There was an overall frequency of $3.64 \%$ of Rhesus negatives.

\section{Conclusion}

The present study indicated that there is a possible association between blood group A and asthma susceptibility. The study revealed the importance of $\mathrm{ABO}$ and $\mathrm{Rh}$ blood typing in the demonstration of atopic diseases like asthma.

\section{Recommendations}

Since asthma is a common chronic inflammatory condition of the lung airways, affecting many people all over the world mostly children; boys and girls. This research was carried out with the aim to offer solution to this problem.

From the result of the current study, it is deem appropriate to recommend as follows;

- That more research needs to be conducted on this area with the aim of eradicating or limiting the prevalence of this disease condition.

- That more effort from government is needed to further enlighten people about predisposing factors and behaviors that can aggravate the condition in affected individuals

- A large scale and molecular based research need to be conducted to establish (if any) the genetic relationship of asthma, so that it can be incorporated in marital counseling to counsel the prospective couple who are likely to give birth to child with asthma.

\section{Author Contributions}

Moses Nnaemeka Alo, Saidu Abdulhi Yaro and Bello Jubril conceived the research and carried out the Laboratory experiments. Bello Jubril, Ukpai Agwu Eze and Nelson Nnanna Nwanoke did the journal search and prepared the manuscript. Moses Nnaemeka Alo and Saidu Abdulhi Yaro reviewed and edited the manuscript. All authors discussed the final copy of the manuscript and approved it.

\section{References}

[1] Yaser MH, Athab MA, Sadiq MA. The association of bronchial asthma to ABO blood groups in Najaf Governorate. Kufa Med. Journal 2008; 11(1): 234-245.

[2] Manisha S, Yadav AS. Distribution of ABO and Rh (D) allele frequency among asthmatic patients. IJRANSS 2014; 2(5): $217-222$

[3] Kumar P, Clarck M. Clinical Madicine, 6th edition. Elsevier Saunders 2009; p.140.

[4] Kumar V, Abbas AK, Fausto N. Robbins and Cotran pathologic basis of disease, 8th edition. Elsevier Saunders 2019; p. 688.

[5] Kauffmann F, Frette C, Pham QT, Nafiss S, Bertrand JP, Oriol R. Association of blood group-related antigens to FEV1, wheezing and asthma. Am J Respir Crit Care Med 1996; 153(1): 76-82.

[6] De la Vega AR, Gómez CJ, Bacallao GJ. Genetic polymorphism of $\mathrm{ABO}$ and $\mathrm{Rh}$ systems in relation to bronchial asthma: a preliminary report. Allergol immunopathol 1976; 4(5): 305-10.

[7] Chen YL, Chen JC, Lin TM, Huang TJ, Wangz ST, Lee MF. $\mathrm{ABO} /$ secretor genetic complex is associated with the susceptibility of childhood asthma in Taiwan. Clin Exp Allergy 2005; 35(7): 926-32.

[8] Brachtel R, Walter H, Beck W, Hilling M. Associations between a topic diseases and the polymorphic systems ABO, Kidd, Inv and red cell acid phosphatase. Hum Genet 1979; 49(3): 337-48.

[9] Bijanzadeh M, Ramachandra NB, Mahesh PA, Savitha MR, Manjunath BS, Jayaraj BS. Lack of association between asthma and ABO blood group. Lung 2009; 187(6): 389-92.

[10] Koers WJ, Houben GF, Berrens L. Blood groups ABO and grass-pollen hay fever. Allerg Immunol (Leipz) 1989; 35(3): 167-72.

[11] Nikitin AV, Vasil'eva LV, Sidel'nikova VI, Vasil'chenko TD. Clinico-genetic parallels in infectious inflammatory diseases of the lungs. Probl Tuberk 1989; 8:7-10.

[12] Mozalevskii AF. Polymorphic blood systems in children with bronchial asthma.Tsitol Genet 1985; 19(3): 220-225.

[13] Khetsuriani NG, Gamkrelidze AG. Erythrocyte antigens as immunogenetic markers of respiratory atopic diseases in Georgians. J Investig Allergol Clin Immunol 1995; 5(1): 35-39.

[14] Hisham EA, Aml AA, Mahmoud ME, Manal AS, Seham AA. (2015) Assessment of Serum Vitamin D in Patients with Bronchial Asthma. Egyptian Journal of Chest Diseases and Tuberculosis 2015; 64(1): 1-5.

[15] Martinez FD. Genes, environments, development and asthma: a reappraisal. Eur Respir J 2007; 29(1): 179-84.

[16] Denborough MA, Downing HJ. Secretor status in asthma and hay fever. J Med Genet 1968; 5(4):302-5.

[17] Ronchetti F, Villa MP, Ronchetti R, Bonci E, Latini L, Pascone R. (2001). ABO/Secretor genetic complex and susceptibility to asthma in childhood. Eur Respir J 2001; 17(6):1236-8. 
[18] Oriol R. ABO, Hh, Lewis and secretion: serology, genetics and tissue distribution. In: Cartron, J.P., Rouger, P. Blood cell biochemistry: molecular basis of human blood group antigens. New York: Plenum; 1995. p.37-73.

[19] Henry SM. Molecular diversity in the biosynthesis of GI tract glycoconjugates: A blood-group-related chart of microorganism receptors. Transfus Clin Biol 2001; 8(3):226-30.

[20] World Health Organization: Fact Sheet No 307: Asthma. 2011. Retrieved October 13, 2014.

[21] Anandan C, Nurmatov U, van Schayck OC, Sheikh A. Is the prevalence of asthma declining? Systematic review of epidemiological studies. Allergy 2010; 65 (2): 152-67.

[22] NHLBI, (2007). National heart, lungs and blood institute Guidelines pp. 167-375. Retrieved on October 17, 2014.

[23] Seaton A, Crompton G. Asthma: Clinical Features. in: Anthony Seaton, Douglas Seaton, A. Gordon, Crofton and Douglas's Respiratory Diseases, 5th ed. 2000, vol. 34(2): 922 972.

[24] El-Sobky MK, Dorgham LS, Farhat TM. ABO blood groups ddistibution and theirs relationship to peptic dyspepsia, bronchial asthma, diabetes mellliitus and hypertension among married couples in rural area in Menoufia governorate. The Egypt J. of Community medicine 1990; 7(2): 159-174.
[25] Egesie UG, Egesie OJ, I. Usar, Johnbull TO. Distribution Of Abo, Rhesus Blood Groups And Haemoglobin Electrophoresis Among The Undergraduate Students Of Niger Delta University Nigeria. Nigerian Journal Of Physiological Sciences 2008; 23(1-2): 5-8

[26] Bakare AA, Azeez MA, Agbolade JO. Gene freqencies of $\mathrm{ABO}$ and rhesus blood groups and haemoglobin variants in Ogbomoso, South-West Nigeria. African Journal of Biotechnology 2006; 5(3):224 - 229.

[27] Adeyemo OA, Soboye JO, Omolade B, (2006). Frequency distribution of $\mathrm{ABO}, \mathrm{RH}$ blood groups and blood genotype among cell biology and genetics students of University Lagos, Nigeria. African Journal of Biotechnology 2006; 5: (22) 2062 -2065 .

[28] Omotade OO, Adeyemo AA, Kayode CM, Falade SL, Ikpeme $\mathrm{S}$ (1999). Gene frequencies of ABO and Rh (D) blood group alleles in a healthy infant population in Ibadan, Nigeria. West African Journal of Medicine 1999; 18: 294-297.

[29] Kulkarni AG, Peter B, Ibazebo R, Dash B, Fleming AF. The $\mathrm{ABO}$ and Rhesus groups in the north of Nigeria. Annals of Tropical Medicine and Parasitology 1985; 79(1): 83-8. 